\title{
A Laboratory Study of the Hydro-Geochemical Behaviour of Paste Tailings Disposal
}

\author{
T. Deschamps, M. Benzaazoua, B. Bussière, T. Belem Université du Québec en Abitibi-Témiscamingue, \\ Canada
}

M. Aubertin École polytechnique de Montréal, Canada

\section{INTRODUCTION}

Cemented paste tailings are used regularly for underground backfilling of open stopes. This technique allows returning acid generating tailings underground, where the backfill serves as ground support. Paste tailings disposal (PTD) on surface have been proposed for some time as an alternative to "traditional" tailings impoundments (e.g., Cincilla et al., 1997), which may be difficult to rehabilitate and responsible for many geotechnical and environmental problems (W.I.S.E., 2005). This technique is already used at the Bulyanhulu gold mine (Tanzania), where tailings are densified, pumped, and deposited as a paste in thin layers (Theriault et al., 2003; Shuttleworth and Thomson, 2005; Theron et al., 2005; McMullen et al., 2005). In this particular case, no binder is added to the paste tailings. However, even if the technique is promising, the interactions of the paste tailings in the disposal area with the local environment are still not well understood.

This paper presents complementary results ensuing from a study performed by Benzaazoua et al. (2004) which presented details on the experimental set-up and background information. More specifically, this paper focuses on: (i) the hydrogeological and geochemical behaviours of paste tailings disposal after a long curing time and (ii) the microstructural and chemical characterisation of the cemented paste tailings.

\section{MATERIAL AND METHODS}

\subsection{Physical model}

This physical model described in Benzaazoua et al. was designed to simulate the physical, geochemical, and hydrogeological behaviours of paste tailings in a disposal facility (Benzaazoua et al., 2004). The model deposition area is $200 \mathrm{~cm}$ in length $\times 50 \mathrm{~cm}$ in width, with the bottom plate equipped with a drainage system and covered by a geotextile. The side-walls (100 cm in height) are made up of Lexan transparent plastic (see Figure 1a) and reinforced with a metal frame. The model is also equipped with 5 sprinklers to simulate wetting-drying cycles. The percolating water can be recovered at the bottom of the model for chemical analyses. Eight TDR (Time Domain Reflectometry) probes and tensiometers have been installed at different elevations (see Figure 1b) to measure volumetric water content and matric suction, respectively, during the wetting and drying tests. In this paper, only the results from the TDR probe measurements are presented. 

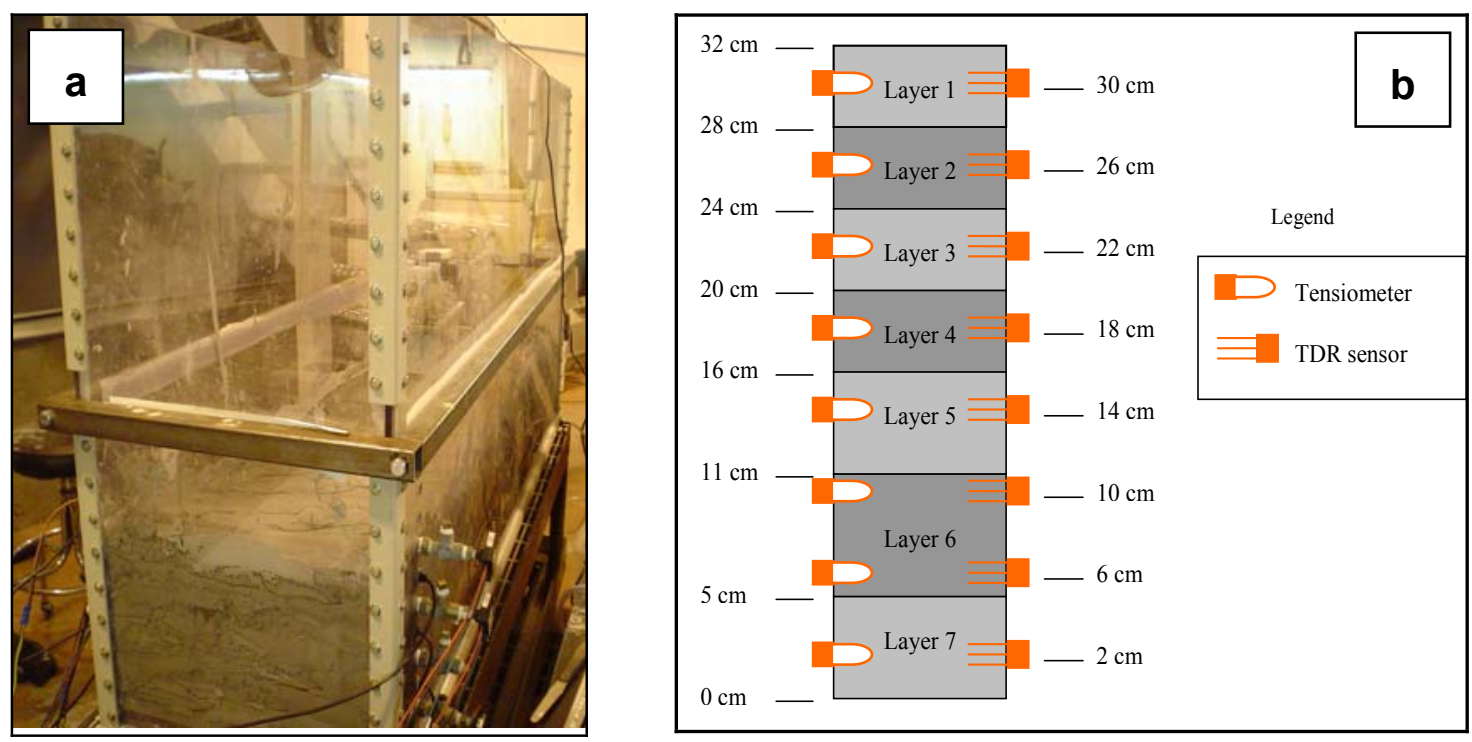

\section{Figure 1 a) Photograph of the experimental set-up, b) Diagram showing the TDR sensors and tensiometers layout and layer thicknesses}

\subsection{Tailings and paste characteristics}

The tailings used in this study were collected from the Doyon gold mine (Cambior Inc.), located in the Abitibi area (Quebec, Canada). Table 1 shows their main physical and chemical properties. The tailings grain-size distribution is relatively fine, which is typical of gold ore processing (the $\mathrm{D}_{10}$ is $4.07 \mu \mathrm{m}$ and the $\mathrm{D}_{50}$ is $\left.23.45 \mu \mathrm{m}\right)$. The fairly high value of the specific surface area $\left(2460 \mathrm{~m}^{2} / \mathrm{kg}\right)$ is due in part to its sericite (fine grained mica) content. The pore water has a relatively high conductivity (5390 $\mu \mathrm{mho})$. The tailings are acid generating $\left(\mathrm{NNP}=-65.2 \mathrm{~kg} \mathrm{CaCO}_{3} / \mathrm{t}\right)$ and their neutralizing potential is low $(\mathrm{NP}=21.8 \mathrm{~kg} \mathrm{CaCO} / \mathrm{t})$. The binder used for the mix preparation is similar to the one used by Doyon mine (i.e. $70 \%$ of slag and $30 \%$ of Portland cement type I) in their paste backfill. Additional details about the chemical composition of the binder can be found in Benzaazoua et al., 2004. The paste mixture has been prepared with a proportion of $2 \%$ binder (by dry solid mass of the total tailings) and tap water in order to obtain the desired paste consistency for surface disposal. A $250 \mathrm{~mm}$ slump was targeted according to Theriault et al. (2003). This slump value corresponds to a solid content of only $66 \%$ due to the specific characteristics of the tailings (fineness and mineralogy).

In the model cell, the cemented paste tailings have been deposited in seven thin layers (about $4 \mathrm{~cm}$ each). The deposition frequency was set at about one layer every 2 to 3 days. As can be seen on Figure $1 \mathrm{~b}$, layer 1 is the top layer and layer 7 is the bottom layer. 


\section{Table $1 \quad$ Tailings main physical and chemicals properties}

\begin{tabular}{|l|l||l|l|}
\hline Parameter & Value & Parameter & Value \\
\hline Specific gravity, $\mathrm{G}_{\mathrm{s}}$ & 2.82 & $\mathrm{D}_{10}$ & $4.07 \mu \mathrm{m}$ \\
\hline pulp density & $79 \%$ & $\mathrm{D}_{50}$ & $23.45 \mu \mathrm{m}$ \\
\hline pH of the pore water & 8.23 & $\mathrm{D}_{90}$ & $96.99 \mu \mathrm{m}$ \\
\hline$\% \mathrm{~S}_{\text {sulphide }}=\% \mathrm{~S}_{\text {tot. }}-\% \mathrm{~S}_{\text {sulphate }}$ & $2.78 \%$ & $\mathrm{AP}$ & $87.0 \mathrm{~kg} \mathrm{CaCO}_{3} / \mathrm{t}$ \\
\hline Conductivity of the pore water & $5390 \mu \mathrm{mho}$ & $\mathrm{NP}($ Lawrence \& Wang, 1997) & $21.8 \mathrm{~kg} \mathrm{CaCO}_{3} / \mathrm{t}$ \\
\hline Specific surface area, $\mathrm{S}_{\mathrm{s}}$ & $2460 \mathrm{~m}^{2} / \mathrm{kg}$ & $\mathrm{NNP}=\mathrm{NP}-\mathrm{AP}$ & $-65.2 \mathrm{~kg} \mathrm{CaCO}_{3} / \mathrm{t}$ \\
\hline
\end{tabular}

\subsection{Experimental tests and analysis}

Volumetric water content measurement: The physical model is equipped with eight TDR sensors. They are installed on the side-walls of the box and spaced at intervals of $4 \mathrm{~cm}$ (see Figure 1b). These sensors measure the paste volumetric water content during the wetting and drying cycles.

Mercury intrusion porosimetry (MIP): A small sample of paste tailings (about $1 \mathrm{~g}$ ) is oven dried (50 degree Celsius), weighed and introduced into the chamber of the MIP apparatus (Micromeritics AutoPore III 9200). The chamber is then filled by mercury. The pressure is gradually increased, forcing mercury to intrude into the pores of the sample. At each pressure increment, the quantity of mercury intruding into the sample is monitored. The result is not the "true" pore size distribution of the sample, but must be understood as a quantitative representation of the actual pore size distribution (for more information see Diamond, 2000, and the following discussions of Wild, 2001; Chatterji, 2001; Diamond, 2001a and 2001b). The MIP is considered an effective tool to detect the pore filling caused by cementation in cemented paste backfill (CPB) (Belem et al, 2001; Ouellet et al., 2004). The most often used parameter to characterize MIP test results is the "threshold diameter", usually defined as the pore size corresponding to the highest volume of mercury intruding into the sample.

Water geochemistry: the leachate (percolated water) collected at the bottom of the physical model was analysed by induced coupled plasma-atomic emission spectroscopy (ICP-AES) (Perkin Elmer Optima 3100RL). The $\mathrm{pH}, \mathrm{Eh}$, and electrical conductivity of the leachate have been also analysed. These results will be compared to the composition of the initial tailings pore water and that of the water collected during the paste deposition.

Paste geochemistry: a sample of each layer (taken after 22 months) was digested (complete digestion by $\mathrm{HNO}_{3}, \mathrm{Br}_{2}, \mathrm{HF}$ and $\mathrm{HCl}$ ) and analysed by ICP-AES. Analyses were also carried out on the crusts formed at the surface of layers 1 and 2 . 


\section{RESULTS}

\subsection{Wetting and drying tests}

\subsubsection{Water flow}

Three wetting and drying tests were carried out: (i) test 1 , after 7 days of curing time, flow rate $=80 \mathrm{l} / \mathrm{h}$ during 57 minutes; (ii) test 2 , after 20 months of curing time, flow rate $=84$ 1/h during 25 minutes, no water collected; and (iii) test 3 , after 21 month of curing time, covered with 28 litres.

Figures 2, 3, and 4 show the results of test 1, test 2, and test 3 respectively. In these figures, bold lines represent the beginning (full line) and the end of the test (dashed line); the wetting begins at time reference $=$ 0 . During the first wetting/drying test, a saturated zone (layers 4 and 5) was observed where the water content remained high even after 2 days of drying (Figure 2).

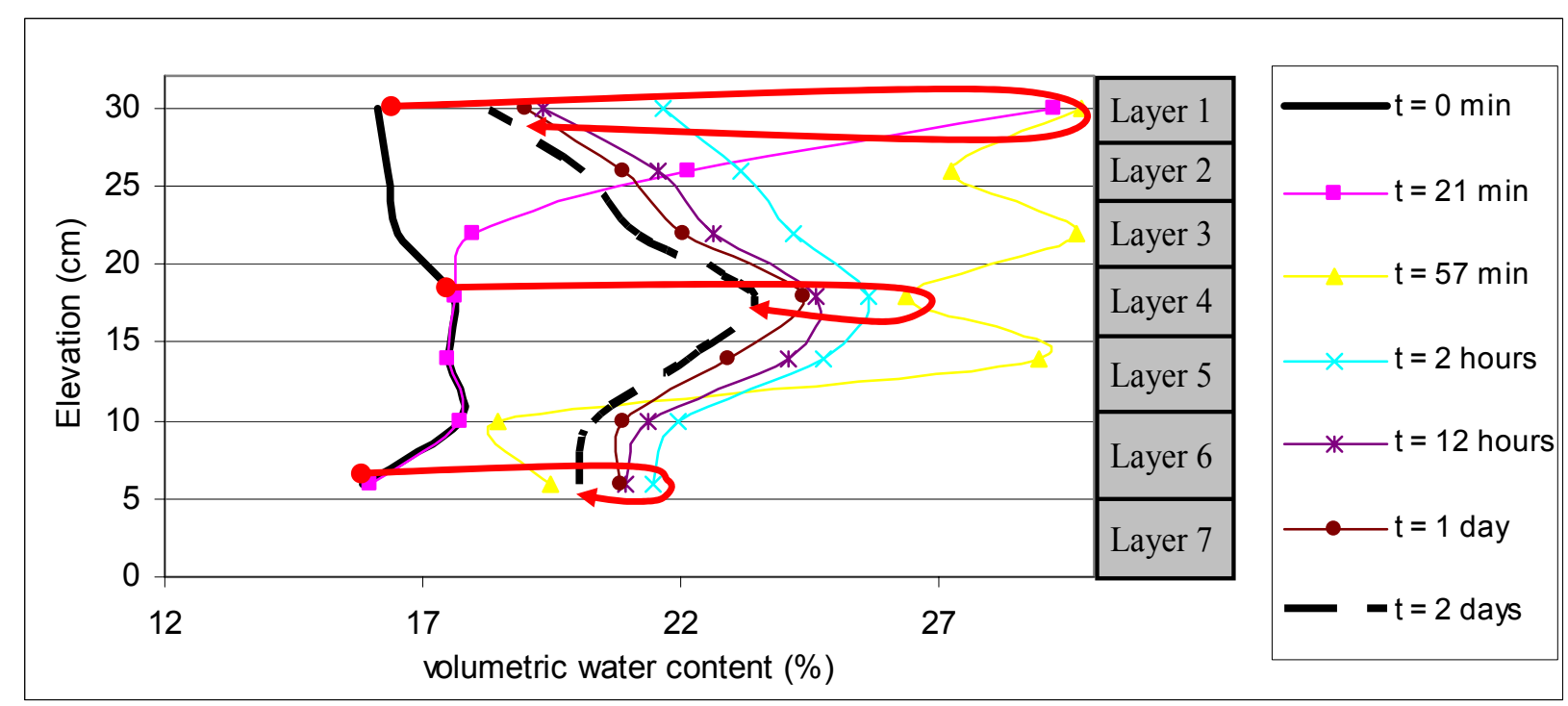

Figure $2 \quad$ Volumetric water content profiles during test 1 (wetting and drying)

During test 2 (Figure 3), layers 1 and 2 very quickly (after 21 and 49 minutes respectively) reached their maximal volumetric water content value. However, the underneath layers reached their maximum water content values after about 7 days. The shape of the final volumetric water content profile of test 2 is quite different compared to the one obtained after test 1 . In the case of test 2 , the volumetric water contents of layers 2 and 6 remained high (Figure 3). 


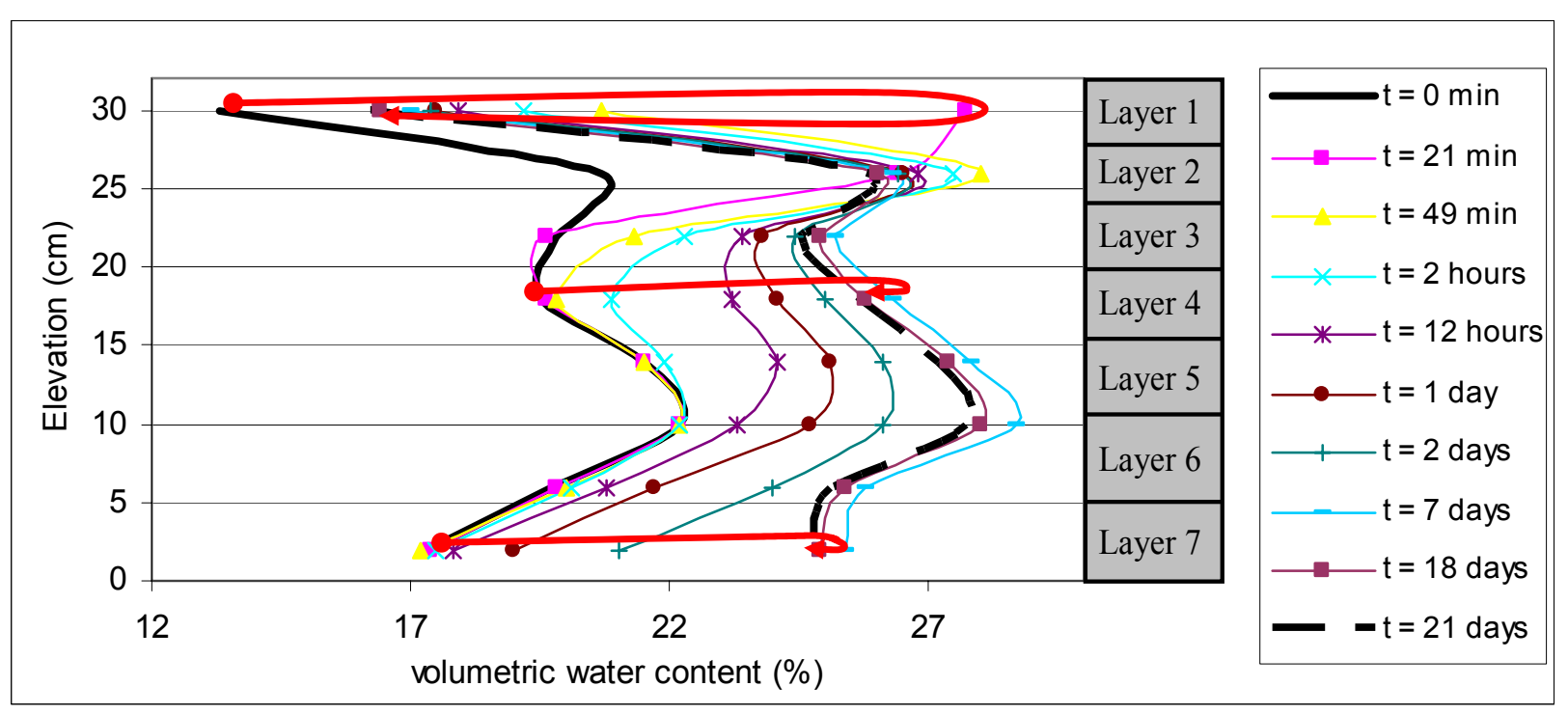

\section{Figure $3 \quad$ Volumetric water content profiles during test 2 (wetting and drying)}

During test 3, the paste was covered with 28 litres of water. Figure 4 shows a first wetting stage where the TDR probe placed at an elevation of $6 \mathrm{~cm}$ (layer 6) indicated a high water content value (46\%) after only 10 minutes. The TDR sensor placed at an elevation of $14 \mathrm{~cm}$ (layer 5) indicated a volumetric water content of about $38 \%$ after 20 minutes. These high measured values do not provide the true volumetric water content of the paste, but it probably indicates that some water has penetrated quickly through existing cracks. During a second stage (after 20 minutes) the volumetric water content profile reached its "natural" shape, and then decreases slowly during the third stage (after 25 hours). It must be noticed that many cracks were observed in the paste during the post-testing phase, with some of them being more than $0.5 \mathrm{~cm}$ wide.

The volumetric water content of the paste decreases faster during test 1 than during tests 2 and 3 . For instance, during test 1 , layer 4 reached a maximum volumetric water content value of $29.7 \%$. This value decreased to $25.9 \%$ after only 24 minutes (after layer 4 has reached its maximum water content value), and to $24.4 \%$ after 15 hours. During test 2, layer 4 reached a maximum volumetric water content of $26.3 \%$; this value decreased to $25.8 \%$ after 9 days and to $25.7 \%$ after 14 days. During test 3 , the maximum water content value of layer 4 was $32.4 \%$; this value then decreased to $31.9 \%$ after 2 days and reached $30.5 \%$ after 12 days. Hence, curing seems to slow down the desaturation process of the paste (see Figure 5). The characterization of the solid supports some of these observations. 


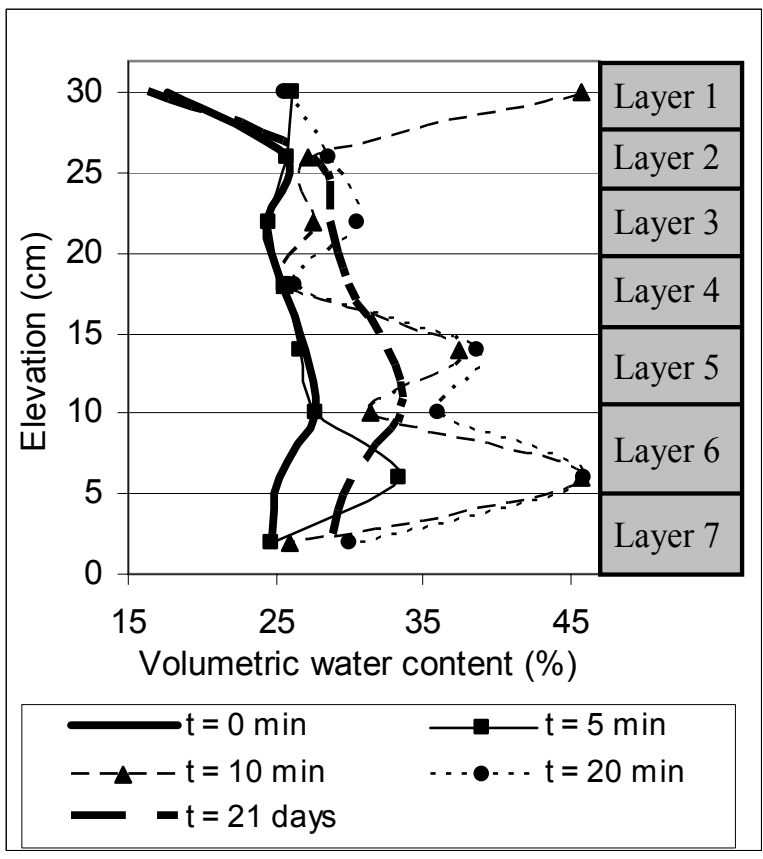

stage 1

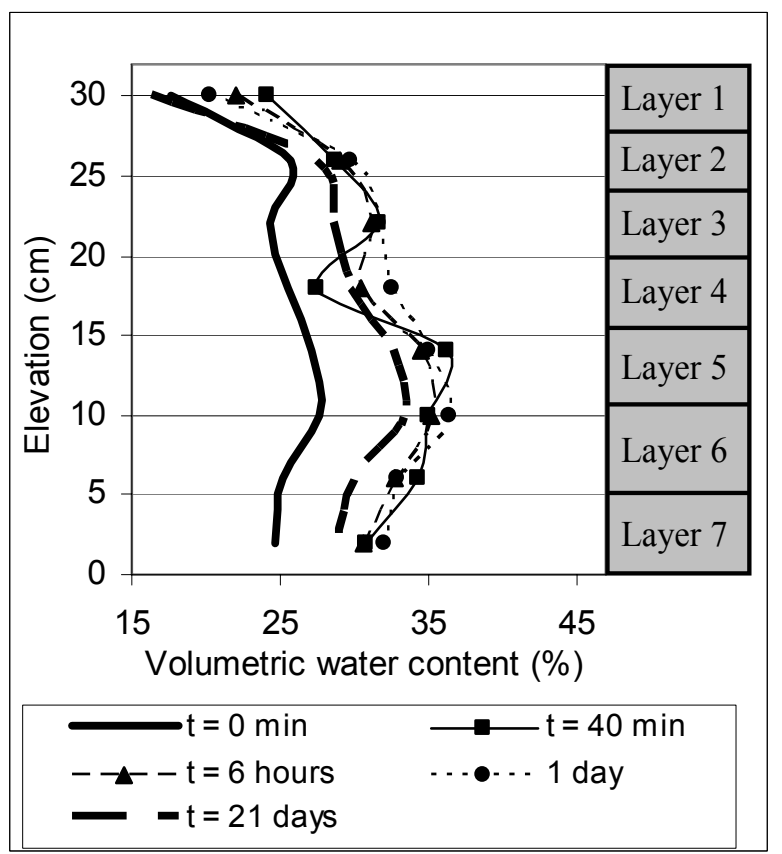

stages 2 and 3

\section{Figure $4 \quad$ Volumetric water content profiles during test 3 (wetting and drying)}

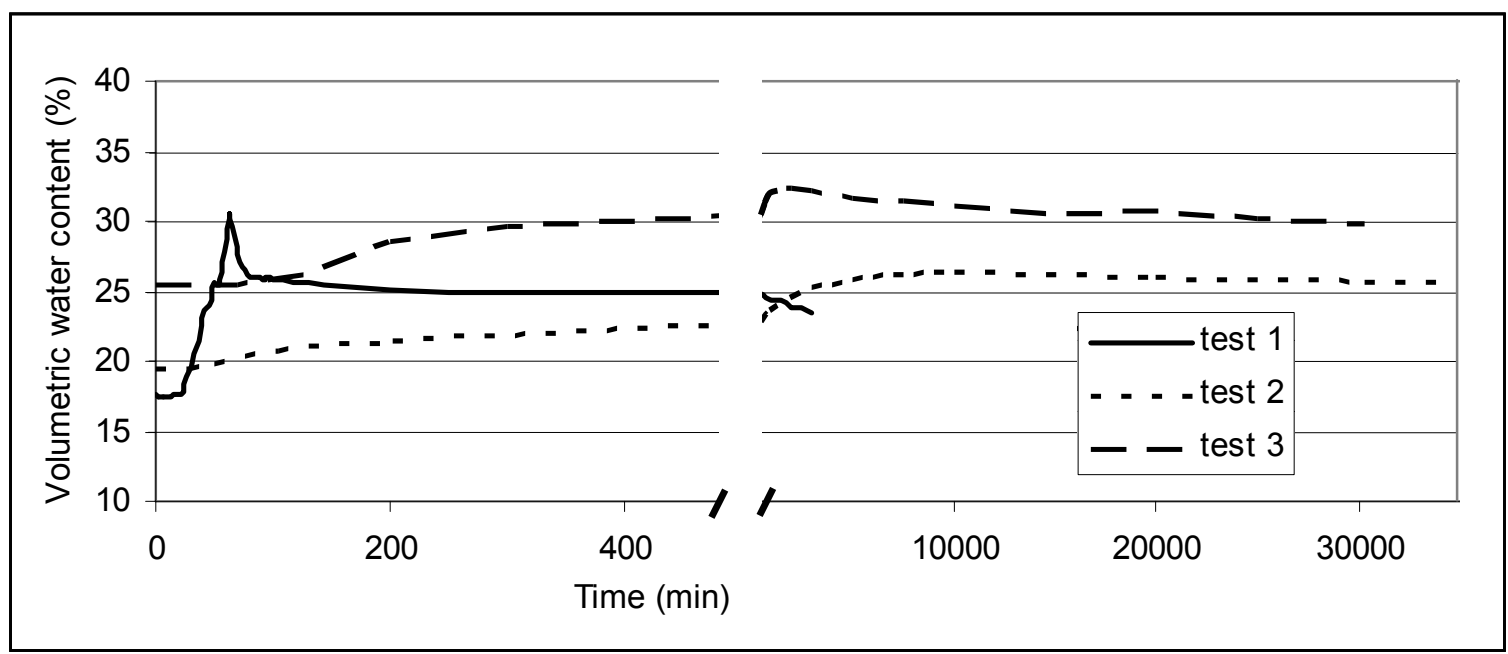

\section{Figure $5 \quad$ Volumetric water content in layer 4 during the three wetting/drying tests}

\subsubsection{Geochemistry of the collected water}

Analyses were carried out on four water samples: (i) tailings initial pore water: TPW; (ii) water collected after layer 1 deposition: $\mathrm{L} 1 \mathrm{~W}$; (iii) water collected from test 1: M1W; and (iv) water collected from test 3: M3W. No water was collected after test 2 . The electrochemical and elemental analyses carried out on the collected seeping waters are presented in Tables 2 and 3.

Calcium and silicon contents were higher in L1W compared to their corresponding amounts in TPW. In addition, the $\mathrm{pH}$ of $\mathrm{L} 1 \mathrm{~W}$ is significantly higher than that of the other solutions, which is indicative of the dissolution of cement phases. This suggests that limited leaching of the binder is occurring (Benzaazoua et 
al., 2004). The pH value of M1W is the same as TPW, and its conductivity is only $2410 \mu$ mho (vs. 5390 $\mu$ mho for TPW). These data suggest that most of mineral species are stabilized within the paste at this stage. However, the $\mathrm{pH}$ of $\mathrm{M} 3 \mathrm{~W}$ has decreased $(\mathrm{pH}=7.6)$ and its conductivity increased to $4810 \mu$ mho (compared to $2410 \mu \mathrm{mho}$ for M1W). Moreover, the amounts of $\mathrm{Ca}, \mathrm{Mg}, \mathrm{Mn}, \mathrm{Mo}, \mathrm{Si}$ and $\mathrm{Zn}$ were higher in M3W. These may indicate additional loss of binder by hydrated cement phase dissolution or reduced stability of other mineral phases due to changes in geochemical conditions within the paste. In particular, it appears that, sulphide oxidation may be occurring, as shown by the sulphate release (3655 ppm for M3W compared to $2060 \mathrm{ppm}$ for M1W). This would explain the release of trace metals that are mobile under circumneutral conditions, such as $\mathrm{Mn}, \mathrm{Mo}$, and $\mathrm{Zn}$, while other trace metals (e.g., $\mathrm{Cu}, \mathrm{Fe}, \mathrm{Al}$ ) might be mobilized but then would be fixed or re-precipitated as secondary phases. Calcium and $\mathrm{Mg}$ would likely be released from neutralizing mineral phases (come mainly from cement) in response to the acidity generated by the sulphide oxidation.

Table 2 Chemical analysis of the collected water

\begin{tabular}{|l|l|l|l|}
\hline Parameters & pH & Eh $(\mathbf{m V})$ & Conductivity ( $\boldsymbol{\mu m h o )}$ \\
\hline TPW & 8.23 & 376 & 5390 \\
\hline L1W & 12.05 & 169.5 & 6680 \\
\hline M1W & 8.13 & 303.8 & 2410 \\
\hline M3W & 7.6 & 324.2 & 4810 \\
\hline
\end{tabular}

Table 3 Elemental analysis of the initial pore water and the collected waters

\begin{tabular}{|c|c|c|c|c|c|c|c|c|c|c|c|c|c|}
\hline Element & Al & As & Ba & Ca & Cu & Fe & Mg & Mn & Mo & Na & SO4 & Si & Zn \\
\hline \multicolumn{10}{|c|}{$(\mathrm{mg} / 1)$} \\
\hline TPW & 0.137 & $<0.03$ & 0.069 & 578 & 0.076 & 0.767 & 1.63 & 0.014 & 0.197 & 644 & 3565 & 2.83 & 0.052 \\
\hline L1W & 0.117 & $<0.03$ & 0.139 & 744 & $<0.01$ & 1.14 & 0.110 & 0.004 & 0.159 & 433 & 3475 & 24.3 & 0.055 \\
\hline M1W & 0.204 & $<0.03$ & 0.048 & 409 & 0.042 & 0.197 & 20.3 & 0.048 & 0.037 & 228 & 2060 & 9.35 & 0.039 \\
\hline M3W & 0.062 & $<0.03$ & 0.060 & 676 & 0.088 & 0.076 & 278 & 1.95 & 0.101 & 49.7 & 3655 & 95.8 & 0.175 \\
\hline
\end{tabular}

\subsection{Post testing characterization}

After the three wetting-drying tests, the side-walls of the physical model were removed in order to sample each paste layer. Afterwards, the samples were analysed (this stage is called "post-testing stage" in this paper). The main observations during the sampling are: a thin crust has formed at the surface of each paste layer (these thin crusts are blackish while the paste is beige); and there are many cracks in the paste, some of them are more than $0.5 \mathrm{~cm}$ in width.

\subsubsection{Microstructure characterization}

Porosity of the paste samples obtained from the post-testing stage was measured by MIP. The results of the MIP measurements indicate that layers 5, 6, and 7 show typical incremental MIP curves encountered in paste backfill, with a well-defined threshold diameter (Ouellet et al., 2004). Layers 1, 2 and 3 show a broader pore size distribution, and their threshold diameters are less well-defined (see Figure 6). For these top layers, the threshold is defined as the value of the first peak on the incremental Hg intrusion-diameter curve. It was also 
observed that layer 4 presents an intermediate MIP curve between upper and lower layers, on which it was difficult to identify a threshold value.

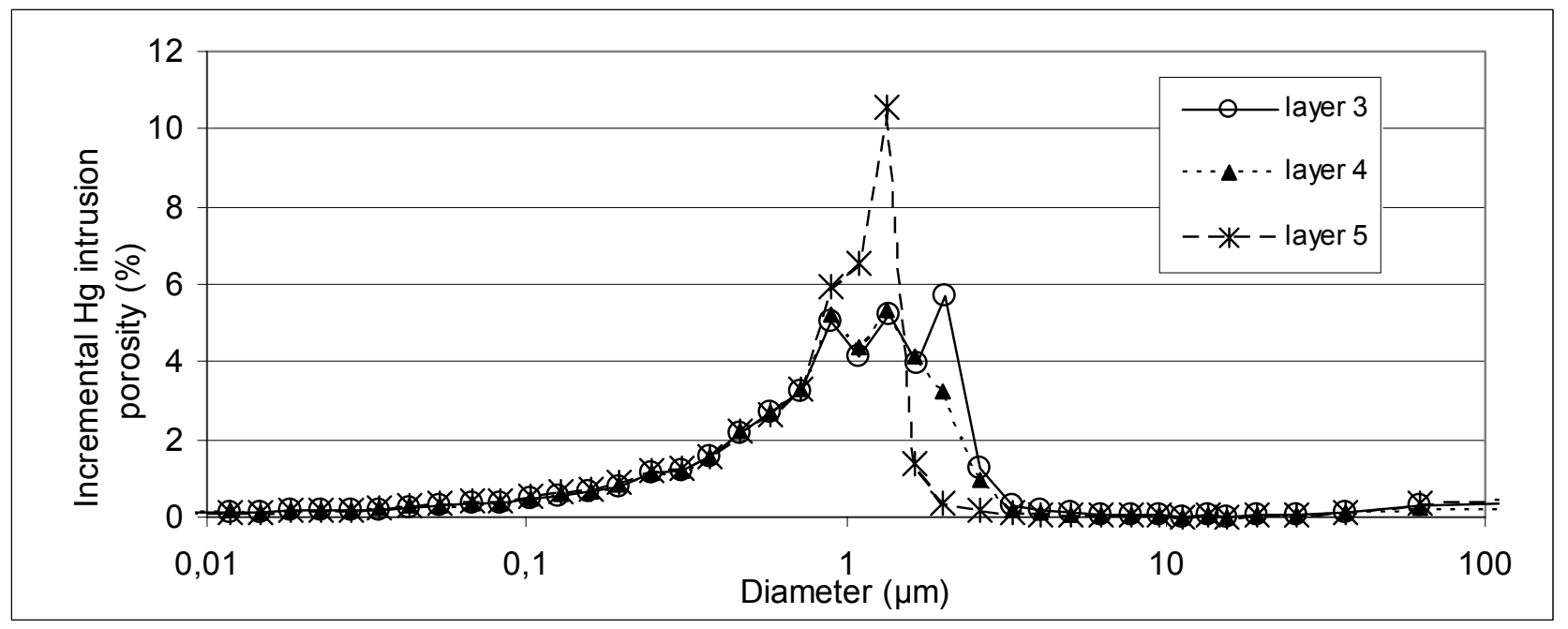

Figure $6 \quad$ MIP curves of the paste for layers 3, 4 and 5

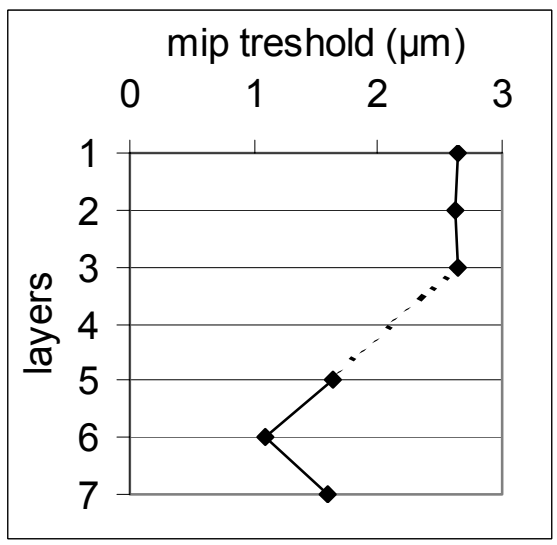

(a) MIP threshold of the 7 layers

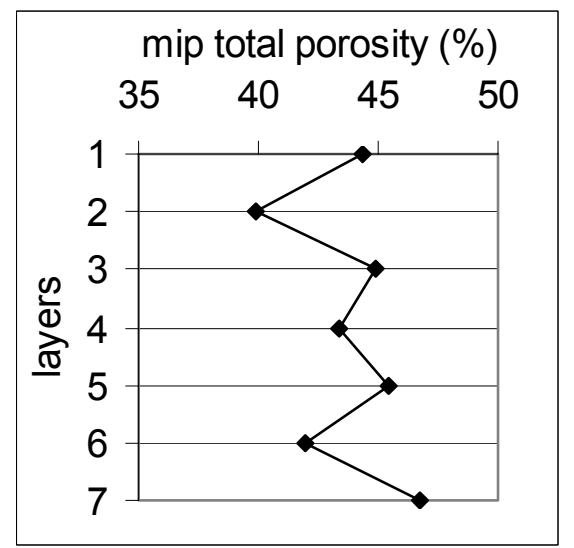

(b) MIP total porosity of the 7 layers

$\begin{array}{ll}\text { Figure } 7 & \text { (a) MIP threshold diameter and (b) MIP total porosity of the seven paste layers }\end{array}$

More specifically, Layers 1, 2, and 3 have threshold values around $2.6 \mu \mathrm{m}$. This value decreases to $1.6 \mu \mathrm{m}$ for layers 5 and 7; and to $1.1 \mu \mathrm{m}$ for layer 6 (see Figure 7a). Figure $7 \mathrm{~b}$ shows that layers 2 and 6 have a lower total MIP porosity than others layers: $38.9 \%$ for layer 2 and $42 \%$ for layer 6 , while the average MIP porosity value for the other layers is about $45 \%$. The shape of the incremental MIP curve of the 3 upper layers seems to indicate that there has been a change in the paste microstructure; average pore sizes are larger than the one of layers 5,6, and 7. However there is no apparent relationship between the MIP total porosity and the threshold diameter (e.g. layer 2 has the lower total porosity but the same threshold as layers 1 and 3). Figure 8 shows the incremental MIP porosity distribution for pore sizes between $0.001 \mu \mathrm{m}$ and 0.1 $\mu \mathrm{m}$ (called "nano-porosity"). One can see that the top layers (layers 1 and 2) have a lower MIP nano-porosity than the other layers. Layer 2 has no MIP porosity under $0.03 \mu \mathrm{m}$ and layer 1 has no MIP porosity under 
$0.004 \mu \mathrm{m}$. This difference seems to indicate a loss of binder in layer 1 and 2 . In fact, the binder phases are entirely responsible for the existence of such small (nano-size) pores.

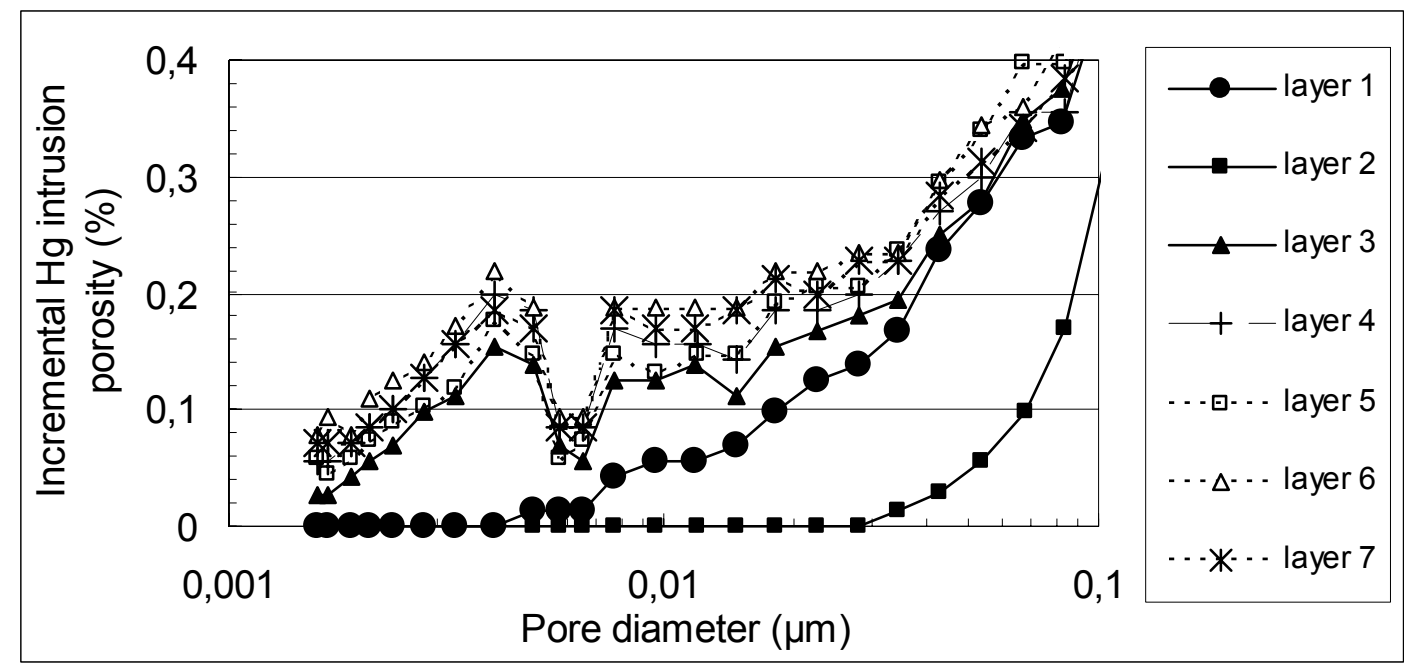

Figure $8 \quad$ MIP curves of the paste for MIP pore size between 0.001 and $0.1 \mu \mathrm{m}$

\subsubsection{Chemistry of the paste}

Table 4 shows the results of the elemental analyses carried out, during the post-testing stage, on each layer and on the crusts encountered on top of the overall deposit (layer 1 crust) and on top of layer 2 (layer 2 crust).

Table $4 \quad$ Elemental analysis of the paste for the 7 layers and the crusts

\begin{tabular}{|c|c|c|c|c|c|c|c|c|c|c|c|c|c|}
\hline Elements & Al & B & $\mathbf{B a}$ & $\mathbf{C a}$ & $\mathbf{C u}$ & $\mathbf{F e}$ & Mg & Mn & $\mathbf{N a}$ & $\mathbf{P}$ & $S$ & $\mathbf{S}_{\text {Sulphate }}$ & $\mathbf{Z n}$ \\
\hline & \multicolumn{13}{|c|}{$\mathrm{wt} \%$} \\
\hline layer 1 crust & 4.14 & 0.025 & 0.047 & 7.56 & 0.065 & 3.34 & 0.821 & 0.043 & 0.333 & 0.034 & 7.73 & n.a. & 0.013 \\
\hline layer 1 & 5.70 & 0.052 & 0.065 & 1.70 & 0.086 & 4.28 & 0.845 & 0.057 & 0.201 & 0.045 & 2.53 & 0.38 & 0.035 \\
\hline layer 2 crust & 5.56 & 0.201 & 0.065 & 4.42 & 0.071 & 3.80 & 0.797 & 0.052 & 0.262 & 0.039 & 4.36 & n.a. & 0.017 \\
\hline layer 2 & 4.67 & 0.050 & 0.053 & 1.68 & 0.078 & 4.07 & 0.693 & 0.051 & 0.184 & 0.043 & 2.65 & 0,41 & 0.021 \\
\hline layer 3 & 5.99 & 0.038 & 0.070 & 1.84 & 0.080 & 4.22 & 0.839 & 0.057 & 0.192 & 0.043 & 2.72 & 0,46 & 0.021 \\
\hline layer 4 & 4.57 & 0.033 & 0.058 & 1.79 & 0.079 & 4.07 & 0.795 & 0.052 & 0.181 & 0.043 & 2.66 & 0,50 & 0.017 \\
\hline layer 5 & 5.98 & 0.046 & 0.070 & 2.03 & 0.077 & 4.17 & 0.835 & 0.057 & 0.188 & 0.043 & 2.71 & 0,56 & 0.015 \\
\hline layer 6 & 5.12 & 0.044 & 0.055 & 1.76 & 0.078 & 4.18 & 0.763 & 0.054 & 0.179 & 0.043 & 2.62 & 0,64 & 0.015 \\
\hline layer 7 & 4.91 & 0.046 & 0.057 & 1.91 & 0.075 & 4.07 & 0.715 & 0.054 & 0.182 & 0.042 & 2.76 & 0,70 & 0.015 \\
\hline
\end{tabular}

n.a.: not analysed

The elemental compositions of the two analyzed crusts are different from the composition of the paste. The amount of $\mathrm{Ca}$ is higher in the crusts: $7.56 \mathrm{wt} \%$ (layer $1 \mathrm{crust}$ ) and $4.42 \mathrm{wt} \%$ (layer 2 crust) in comparison to values between 1.68 and $2.03 \mathrm{wt} \%$ for the seven paste layers. The same difference was observed in term of sulphur content: $7.73 \mathrm{wt} \%$ (layer 1 crust) and $4.36 \mathrm{wt} \%$ (layer 2 crust) versus values between 2.53 and 2.73 wt $\%$ in the paste layers. The higher amounts of calcium and sulphur in the crusts suggest the presence of secondary minerals such as gypsum, which is a very common occurrence on the surface of tailings that contain reactive sulphides. 
Except for the sulphate, no meaningful trends can be detected in terms of the elemental analyses of the seven paste layers (Table 4). The amount of sulphate increases with the depth (from $0.38 \mathrm{wt} \%$ at the top to $0.70 \mathrm{wt} \%$ at the bottom, Figure 9). In the first layer, $15.1 \%$ of the total sulphur comes from the sulphate. This proportion increases to $25.2 \%$ in layer 7 . This suggests that oxidation and leaching of the sulphate have started during the test. The increase of the sulphate amount with depth may be explained by the reprecipitation of sulphate generated in the upper layers.

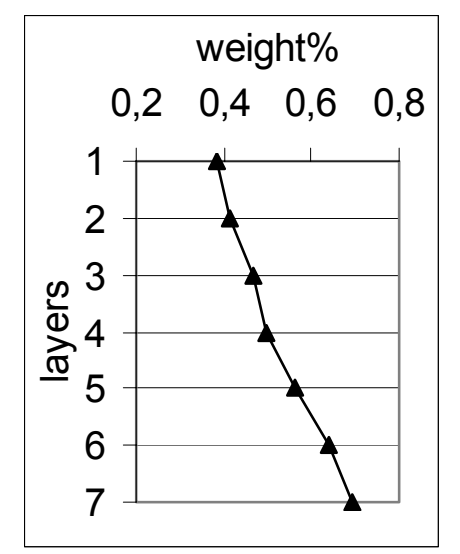

a) wt $\%$ of $S_{\text {sulphate }}$

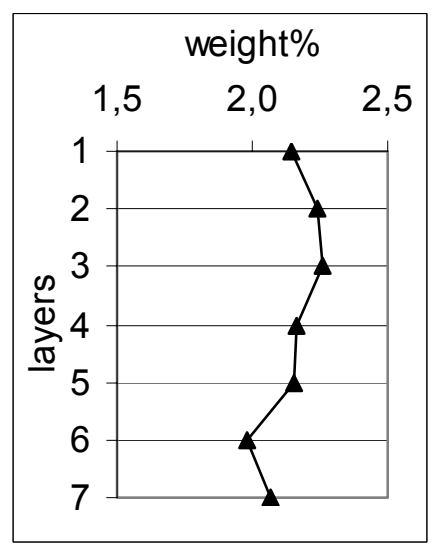

b) $\mathrm{wt} \%$ of $\mathrm{S}_{\text {sulphide }}$

Figure 9 Sulphur species distributions in the seven paste layers

\section{CONCLUSION}

This paper presents the results of an experimental study carried out with a physical model simulating surface paste disposal. The study shows that the volumetric water content of the cemented paste decreases slower after 21 months than after 7 days of curing time. During wetting-drying test 1 , the water content remains high in layers 4 and 5 (of a total of 7 layers) while after wetting-drying tests 2 and 3, layers 2 and 6 have the highest water contents. Thus the ensuing shapes of the volumetric water content profiles are different depending on the age of the paste. Layers 2 and 6 have the lowest porosity, so there might be a relationship between water retention properties and total porosity (volumetric water content seems to remain higher in low-porosity layers), but the threshold diameter seems to have no influence on the desaturation speed. The results of the MIP tests show that the three top layers and the bottom three layers microstructure are different. The near absence of nano-porosity in layers 1 and 2 seems to indicate a loss of binder. Water geochemistry also confirms that there is some binder loss after 20 months of curing time. The sulphate distribution in the paste suggests that sulphide oxidation occurred. A thin crust forms at the top of each paste layer. The amounts of calcium and sulphur are elevated in these crusts, which may indicate an enhanced presence of secondary minerals such as gypsum. To complete this work, additional solid characterization (e.g., mineralogical analysis by x-ray diffraction) will be done. Also, other tests will be carried out using the same physical model with different deposition scenarios. 


\section{ACKNOWLEDGEMENTS}

The authors would like to acknowledge the financial contributions of NSERC, the Canada Research Chair on "Integrated management of sulphidic mine waste using fill technology", and the Industrial NSERC Polytechnique - UQAT Chair on Environment and Mine Wastes Management.

\section{REFERENCES}

Belem, T., Bussière, B. and Benzaazoua, M. (2001) The effect of microstructural evolution on the physical proprieties of paste backfill. Tailings and mine waste '01, Balkema, Rotterdam, pp. 365-374.

Benzaazoua, M., Pérez, P., Belem, T. and Fall, M. (2004) A laboratory study of the behaviour of surface paste disposal. Proceedings of the 8th international symposium on mining with backfill, Beijing (China).

Chatterji, S. (2001) A discussion of the paper "Mercury porosimetry - an inappropriate method for measurement of pore size distribution in cement-based materials". Cement and concrete Research 31, pp. 1657-1658.

Cincilla, W.A., Landriault, D.A. and Verburg, R. (1997) Application of paste technology to surface disposal of mineral wastes. Proceedings of the $4^{\text {th }}$ international conference on tailings and mine wastes '97, Fort Collins, Colorado, pp. 343,356.

Diamond, S. (2000) Mercury porosimetry - An inappropriate method for the measurement of pore size distributions in cement-based materials. Cement and concrete research 30, pp. 1517-1525.

Diamond, S. (2001a) Reply to the discussion by S. Wild of the paper "Mercury porosimetry - an inappropriate method for measurement of pore size distribution in cement-based materials". Cement and concrete research 31, pp. 1655-1656.

Diamond, S. (2001b) Reply to the discussion by S. Chattery of the paper "Mercury porosimetry - an inappropriate method for measurement of pore size distribution in cement-based materials". Cement and concrete research 31, pp. 1659.

McMullen, J., Martin, V. and Aubertin, M. (2005) Les résidus en pâte et la déposition en surface des rejets de concentrateur. Symposium 2005 sur l'environnement et les mines, Rouyn-Noranda.

Ouellet, S., Bussière, B., Benzaazoua, M., Aubertin M. and Belem, T. (2004) Effect of binder type and mixing water chemistry on microstructural evolution of cemented paste backfill. 57th Canadian Geotechnical Conference and 5th joint IAH-CNC-CGS Conference, "Geo-engineering for society and its environment". 24-26 October, Quebec city, Canada.

Shuttleworth, J.A. and Thomson, B.J. (2005) Surface paste disposal at Bulyanhulu - Practical lessons learned. Proceeding of the 6th International Seminar on Paste and Thickened Tailings - Paste 2005, Santiago Chile, April 20-22.

Theriault, J.A., Frostiak, J. and Welch, D. (2003). Surface disposal of past tailings at the Bulyanhulu gold mine, Tanzania. Proceedings of Sudbury Mining and Environment Conference.

Theron, M., Addis, P.C., Wates, J.A. and Martin, V. (2005) Paste tailings facility: Relating the unsaturated properties of gold tailings to rate of rise. Proceeding of the 6th International Seminar on Paste and Thickened Tailings - Paste 2005, Santiago Chile, April $20-22$.

Wild, S. (2001) A discussion of the paper "Mercury porosimetry - an inappropriate method for measurement of pore size distribution in cement-based materials". Cement and concrete Research, 31, pp. 1653-1654.

World Information Service on Energy (W.I.S.E.) (2005) Chronology of major tailings dam failures. http://www.wiseuranium.org/mdaf.html, updated 4 Aug 2005. 